\title{
A decision-making model for non-traditional machining processes selection
}

\author{
Kanika Prasad and Shankar Chakraborty*
}

Department of Production Engineering, Jadavpur University, Kolkata - 700 032, West Bengal, India

\section{CHR ON I C L E A B T R A T}

Article history:

Received March 14, 2014

Accepted July 25, 2014

Available online

July 312014

Keywords:

Decision making

Non-traditional machining

process

Expert system

Quality function deployment

\begin{abstract}
Non-traditional machining (NTM) refers to a variety of thermal, chemical, electrical and mechanical material removal processes, developed to generate complex and intricate shapes in advanced engineering materials with high strength-to-weight ratio. Selection of the optimal NTM process for generating a desired feature on a given material requires the consideration of several factors among which the type of the work material and shape to be machined are the most significant ones. Presence of a large number of NTM processes along with their complex characteristics and capabilities, and lack of experts in NTM process selection domain compel for development of a structured approach for NTM process selection for a given machining application. Thus, the objective of this paper is set to develop a decision-making model in Visual BASIC 6.0 to automate the NTM process selection procedure with the help of graphical user interface and visual decision aids. It is also integrated with quality function deployment technique to correlate the customers' requirements (product characteristics) with technical requirements (process characteristics). Four illustrative examples are also provided to demonstrate the potentiality of the developed model in solving NTM process selection problems.
\end{abstract}

(C) 2014 Growing Science Ltd. All rights reserved.

\section{Introduction}

Non-traditional machining (NTM) processes are defined as a group of processes that remove excess material from the workpiece surface by various techniques, involving mechanical, thermal, electrical or chemical energy or combinations of these energies (Pandey \& Shan, 1981). They do not use sharp cutting tools, as it needs to be used for conventional machining processes. Material removal rate of the conventional processes is constrained by the mechanical properties of the workpiece material. In conventional machining processes, the relative motion between the tool and workpiece is typically rotary or reciprocating. Thus, the shape of the work surfaces is limited to circular or flat shapes, and except in CNC systems, machining of three-dimensional surfaces is still a difficult task. In contrast, NTM processes harness energy sources, and material removal is basically accomplished with electrochemical reaction, high temperature plasma, and high velocity jets of liquids and abrasives. In

* Corresponding author. Fax:+91-033-2414-6153

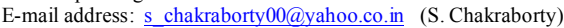

C 2014 Growing Science Ltd. All rights reserved. doi: $10.5267 /$ j.ds1.2014.7.002 
these processes, as there is no physical contact between the tool and workpiece, they can easily deal with the present day difficult-to-cut materials, like ceramics and ceramic-based tool materials, fiber reinforced materials, tungsten carbides, stainless steels, high speed steels, carbides, titanium-based alloys etc. for generating small cavities, slots, slits, blind or through holes at micro- and even at nanolevel (Jain, 2005). Now the conventional machining processes are being substituted by these NTM processes in response to increased demands in industry for better, more consistent workpiece quality; higher production efficiency in processing of hard, tough materials, workpieces with unusual finishing requirements; and capability of machining of parts with complex shapes that require processing beyond the normal capabilities of the conventional machining processes.

In order to exploit the full potential of the NTM processes to generate complex and intricate shape features with the required dimensional accuracy, tolerance and surface finish on the difficult-tomachine materials, it is always recommended that the best NTM is to be selected for the given machining application. Selecting the most appropriate NTM process for a given shape feature and work material combination is often a time consuming and challenging task as it requires consideration of several conflicting criteria (like maximization of material removal rate and minimization of surface finish, maximization of efficiency and minimization of power requirement, etc.), and a vast array of machining capabilities and characteristics of NTM processes. A particular NTM process found suitable under the given conditions may not be equally efficient under other conditions. Therefore, a careful selection of NTM process for a given machining problem is essential while considering the following important attributes:

a) physical and operational characteristics of NTM processes,

b) capability of machining different shapes of work material,

c) applicability of different processes to various types of materials, and

d) economics of various NTM processes.

Thus, the selection procedure involves identifying the relevant possible alternatives among the NTM processes and grading them according to their performance. As the NTM process selection is quite difficult requiring human expertise and being affected by several criteria, there is always a need for a structured approach for appropriate NTM process selection for a given machining application. In this paper, a decision-making model is framed and developed in Visual BASIC 6.0 to automate the NTM process selection procedure for a specified work material and shape feature combination. It is also integrated with quality function deployment (QFD) technique to take into account the customers' requirements (product characteristics) as well as technical requirements (process characteristics) for a given NTM process selection problem.

\section{Literature review on NTM process selection}

Coğun (1993) used an interactively generated 16-digits classification code to eliminate unsuitable NTM processes from consideration and rank the remaining efficient processes. Yurdakul and Coğun (2003) presented a multi-attribute selection procedure integrating technique for order performance by similarity to ideal solution (TOPSIS) and analytic hierarchy process (AHP) to help the manufacturing personnel in determining suitable NTM processes for given application requirements. Chakraborty and Dey (2006) designed an AHP-based expert system with a graphical user interface for NTM process selection. It would depend on the logic table to discover the NTM processes lying in the acceptability zone, and then select the best process having the highest acceptability index. Chakraborty and Dey (2007) proposed the use of a QFD-based methodology to ease out the optimal NTM process selection procedure. Das Chakladar and Chakraborty (2008) developed an expert system while combining TOPSIS and AHP methods for selecting the most appropriate NTM process for a specific work material and shape feature combination. 
Edison Chandrasselan et al. (2008) developed a web-based knowledge base system for identifying the most appropriate NTM process to suit specific circumstances based on the input parameter requirements, like material type, shape applications, process economy and some of the process capabilities, e.g. surface finish, corner radii, width of cut, length-to-diameter ratio, tolerance etc. Das Chakladar et al. (2009) presented a digraph-based approach to solve the NTM process selection problems with the help of graphical user interface and visual aids. Das and Chakraborty (2011) developed an analytic network process (ANP)-based approach to select the most appropriate NTM process for a given machining application taking into account the interdependency and feedback relationships among various criteria affecting the NTM process selection decision. An ANP solver was also developed to automate the entire NTM process selection decision procedure. Sadhu and Chakraborty (2011) applied the input-minimized-based Charnes, Cooper and Rhodes (CCR) model of data envelopment analysis to shortlist the efficient NTM processes for a given application, and then employed a weighted-overall efficiency ranking method to rank those efficient processes. Chakraborty (2011) employed multi-objective optimization on the basis of ratio analysis (MOORA) method to select the most suitable NTM process for a given work material and shape feature combination.

Karande and Chakraborty $\left(2012^{\mathrm{a}}\right)$ integrated PROMETHEE (preference ranking organization method for enrichment evaluation) and GAIA (geometrical analysis for interactive aid) methods for NTM process selection for a specific machining application. Karande and Chakraborty $\left(2012^{\mathrm{b}}\right)$ applied reference point approach for choosing the most suitable NTM processes for generating cylindrical through holes on titanium and through cavities on ceramics. Chatterjee and Chakraborty (2013) explored the applicability of evaluation of mixed data (EVAMIX) method for solving the NTM process selection problems with the help of three demonstrative examples. Temuçin et al. (2014) proposed a decision support model to assess potentials of seven distinct NTM processes in the cutting process of carbon structural steel with the width of plate of $10 \mathrm{~mm}$. Although the past researchers have designed and augmented different expert system models/decision support systems for selecting the best NTM processes for varying machining applications, but no attempt has been put till date to identify the most desirable characteristics of the selected NTM processes and guide the process engineers while providing the possible parametric settings of those processes. In this paper, a decision-making model is thus developed to reduce the gap between the prediction of the best NTM processes and real time machining requirements.

\section{Development of a QFD-based NTM process selection framework}

QFD is a 'method to transform user demands into design quality, to deploy the functions forming quality, and to deploy methods for achieving the design quality into subsystems and component parts, and ultimately to specific elements of the manufacturing process', as described by Akao (1990). QFD is thus a way to assure the design quality while the product is still in the design stage. From this definition, QFD can be seen as a process where the consumer's voice is valued to carry through the whole process of production and services in order to achieve the highest customer satisfaction. Thus, QFD helps in bringing the customer's voice into the production process to reduce the unnecessary cost and time by designing the product right at the first time itself. Customers' requirements and their relationships with technical requirements are the driving force for the QFD-based methodology. It enables an organization to build quality in a product or service. The primary tool used in QFD is the House of Quality (HOQ), because of its ability to be adapted to the requirements of a particular product. HOQ employs a series of matrices to quantify customer requirements, product ratings and technical requirements. HOQ looks like a house, made up of six major components. These include customers' requirements - what do customers want, phrases customers use to describe products and product characteristics; technical requirements - how customers' needs can be achieved; a planning matrix - shows the weighted importance of each requirement that the organization attempts to fulfill; an interrelationship matrix - establishes a connection between the customer's requirements and 
technical requirements of a product; a technical correlation matrix - referred as roof of the matrix, depicts relationship among technical requirements; and a technical priority matrix - shows the priorities assigned to technical requirements (Hauser \& Clausing, 1988; Govers, 1996). The importance weight of each technical requirement can be calculated through simple mathematical expression, while identifying the correlation among all these factors (Chan \& Wu, 2005). An excellent overview on the applications of QFD technique in diverse fields of engineering and management can be available in (Chan \& Wu, 2002). Although the HOQ matrix may take different forms depending on the type and complexity of the problem, a simplified form of HOQ matrix is considered here taking into account only the prioritized technical requirements at the base of the matrix.

The opening window of the developed decision-making model is shown in Fig. 1 to guide the process engineers selecting the most suitable NTM process for a given work material and shape feature combination. In the HOQ matrix, as shown in Fig. 2, type of the work material, machining cost, toxicity/contamination, machining time, shape feature, accuracy, aesthetics, power consumption, easiness of use, availability of the consumables and tool wear are shortlisted to be the major customers' requirements (product characteristics). These customers' requirements are placed along the rows of the HOQ matrix. On the other hand, along the columns of the same HOQ matrix, tolerance (in $\mathrm{mm}$ ), surface finish (in $\mu \mathrm{m}$ ), surface damage (in $\mu \mathrm{m}$ ), corner radii (in $\mathrm{mm}$ ), taper (in $\mathrm{mm} / \mathrm{mm}$ ), power requirement (in $\mathrm{kW}$ ), material removal rate $\left(\mathrm{mm}^{3} / \mathrm{min}\right)$, work material, safety and cost are considered as the technical requirements (process characteristics). These product characteristics and process characteristics for the developed HOQ matrix for NTM process selection are shortlisted only after considering the valuable opinions of the process experts and after a detailed review of the past research works. Among these process characteristics, work material (1-3), safety (1-5) and cost (1-9) are expressed using qualitative scales, and the remaining has absolute numerical values.

In the HOQ matrix, the beneficial or non-beneficial characteristic of the customers' requirements is identified by the corresponding improvement driver value ( +1 for beneficial criteria and -1 for nonbeneficial criteria). Thus, among the considered product characteristics, machining cost, power consumption and tool wear, being non-beneficial attributes, always require minimum values for the selection of the NTM process. On the other hand, in the HOQ matrix, power requirement and cost are identified as the non-beneficial process characteristics. In this HOQ matrix, the relative importance (priority) of the product characteristics can be evaluated using a fuzzy priority scale having triangular membership function with scale values set as 1 - not important, 2 - important, 3 - much more important, 4 - very important and 5 - most important. For filling up the HOQ matrix and developing the interrelationship matrix between product characteristics and process characteristics, again a fuzzy priority scale is proposed as 1 - very very weak relation, 2 - very weak relation, 3 - weaker relation, 4 - weak relation, 5 - moderate relation, 6 - strong relation, 7 - stronger relation, 8 - very strong relation and 9 - very very strong relation. These triangular fuzzy numbers for providing the relative importance of product characteristics and process characteristics are later defuzzified using the centroid method. Once the HOQ matrix is filled up with the necessary information, the weight for each process characteristic is computed using the following equation:

$w_{j}=\sum_{i=1}^{n} P r_{i} \mathrm{x} I D_{i} \mathrm{x}$ correlation index,

where $w_{j}$ is the weight for $j^{\text {th }}$ process characteristic, $n$ is the number of product characteristics, $\operatorname{Pr}_{i}$ is the defuzzified priority assigned to $i^{\text {th }}$ product characteristic, $I D_{i}$ is the improvement driver value for $i^{\text {th }}$ product characteristic and correlation index is the defuzzified value obtained from the HOQ matrix with respect to $j^{\text {th }}$ process characteristic for $i^{\text {th }}$ product characteristic. Instead of setting the priorities of the product characteristics, and inputting the relative associationship between product characteristics and process characteristics in terms of triangular fuzzy numbers, the developed QFD- 
based decision-making model can also be used under a group decision-making environment involving the opinions of three process engineers. In that case, the aggregated preferences can be obtained using a simple arithmetic averaging technique.

In this NTM process selection model, the following NTM processes, work materials and shape features are considered based on which the best NTM process is to be chosen for a given machining application.

NTM process: a) abrasive jet machining (AJM), b) chemical machining (CHM), c) electron beam machining (EBM), d) electrochemical machining (ECM), e) electro discharge machining (EDM), f) laser beam machining (LBM), g) plasma arc machining (PAM), h) ultrasonic machining (USM), and i) water jet machining (WJM).

Work material: a) aluminium, b) steel, c) super alloys, d) titanium, e) refractories, f) plastics, g) ceramics, and h) glass.

Shape feature: a) deep through cutting, b) shallow through cutting, c) double contouring, d) surface of revolution, e) precision small holes (diameter $\leq 0.025 \mathrm{~mm}$ ), f) precision small holes (diameter $>0.025$ $\mathrm{mm}), \mathrm{g})$ standard holes with $\mathrm{L} / \mathrm{D}$ ratio $\leq 20(\mathrm{~L} / \mathrm{D}=$ slenderness ratio $), \mathrm{h})$ standard holes with $\mathrm{L} / \mathrm{D}$ ratio $>20$, i) precision through cavities, and j) standard through cavities.

\section{Demonstrative examples}

In order to demonstrate the application modality of the QFD-based decision-making model, developed in Visual BASIC 6.0 in an Intel ${ }^{\circledR}$ Core $^{\mathrm{TM}}$ i5-2450M CPU @ 2.50 GHz, 4.00 GB RAM operating platform, the following four NTM process selection examples are cited.

\subsection{Example 1: standard holes on super alloys}

In this example, where standard holes are to be generated on super alloys, the process engineer needs to first fill up the HOQ matrix taking into account the interrelations between various product characteristics and process characteristics using the adopted fuzzy scale, as exhibited in Fig. 2. Now, when the user clicks the 'Weight' functional key, the priority weights of all the process characteristics are automatically calculated, based on Eq. (1). These priority weights are subsequently used for the final ranking and selection of the feasible NTM processes. This selection procedure is based on the computation of the performance scores of the feasible NTM processes, while applying the following expression:

Performance score $\left(P S_{i}\right)=\sum_{j=1}^{n} w_{j} \times(\text { Normalized value })_{i j}(i=1,2, \ldots, m ; j=1,2, \ldots, n)$

where $m$ is the number of the feasible NTM processes and $n$ is the number of process characteristics. The normalized values are obtained from the decision matrix of a given NTM process selection problem.

In Fig. 3, the work materials are chosen as super alloys and generation of standard holes (diameter $=$ $0.9 \mathrm{~mm}$ and depth $=1.1 \mathrm{~mm}$ ) is the required machining operation. Now, when the 'Feasible NTM process(es)' functional key is pressed, AJM, CHM, EBM, ECM, EDM, LBM and USM are selected as the candidate NTM processes that can generate standard holes on super alloys. In this window, the user also needs to choose a list of criteria from the drop-down menu for the final selection of the NTM process for the specified application. In this example, cost, material removal rate, taper, surface damage, surface finish and work material are identified as the six influencing criteria affecting the NTM process selection decision. Now, on pressing of the 'Next' key, the final NTM process selection 
window of Fig. 4 is displayed along with the corresponding decision matrix showing the relevant characteristics of the shortlisted NTM processes. In this figure, the performance scores and ranks of the feasible NTM processes, as computed using the QFD methodology, are also provided. It is observed that for generating standard holes of the specified dimensions on super alloys, EBM is the most appropriate NTM process, followed by ECM. AJM and USM processes have limited capabilities for this machining application. For the same machining operation, using an integrated TOPSIS and AHP method, Yurdakul and Coğun (2003) derived the ranking of the feasible NTM processes as ECM-LBM-EBM-CHM-AJM-USM-EDM. On the other hand, using the developed QFD-based model, a ranking of the feasible NTM processes is achieved as EBM-ECM-CHM-LBMEDM-AJM-USM. In Fig. 4, it is observed that there is a negligible difference in the performance scores between EBM and ECM processes, and thus, these two NTM processes can be treated to have almost the same capability to generate standard holes on super alloys.

Now, when the 'Display' functional key is pressed, the feasible NTM processes are graphically ranked, the detailed characteristics of the finally chosen NTM process (EBM) are shown, a typical EBM setup is displayed, and the parametric settings of the EBM process are provided to guide the concerned process engineer. In this example, it is found that the finally selected EBM process has the characteristic values as cost $=1$ (minimum), material removal rate $=2 \mathrm{~mm}^{3} / \mathrm{min}$, taper $=0.02$ $\mathrm{mm} / \mathrm{mm}$, surface damage $=100 \mu \mathrm{m}$, surface finish $=3 \mu \mathrm{m}$ and work material $=2$ (moderate). The output of the developed model also guides the process engineers to set values of different EBM process parameters as pulse duration $=0.05-15 \mathrm{~ms}$, beam current $=0.02-1 \mathrm{~A}$, accelerating voltage $=$ $150-200 \mathrm{kV}$ and energy per pulse $=50-150 \mathrm{~J}$. These process parameter values are only the tentative settings of the EBM process, the final parametric combinations would entirely depend on the requirements of the process engineers and technical specifications of the EBM setup. Finally, the process engineer has to be fine tune all these settings to attain the optimal machining performance of the EBM process.

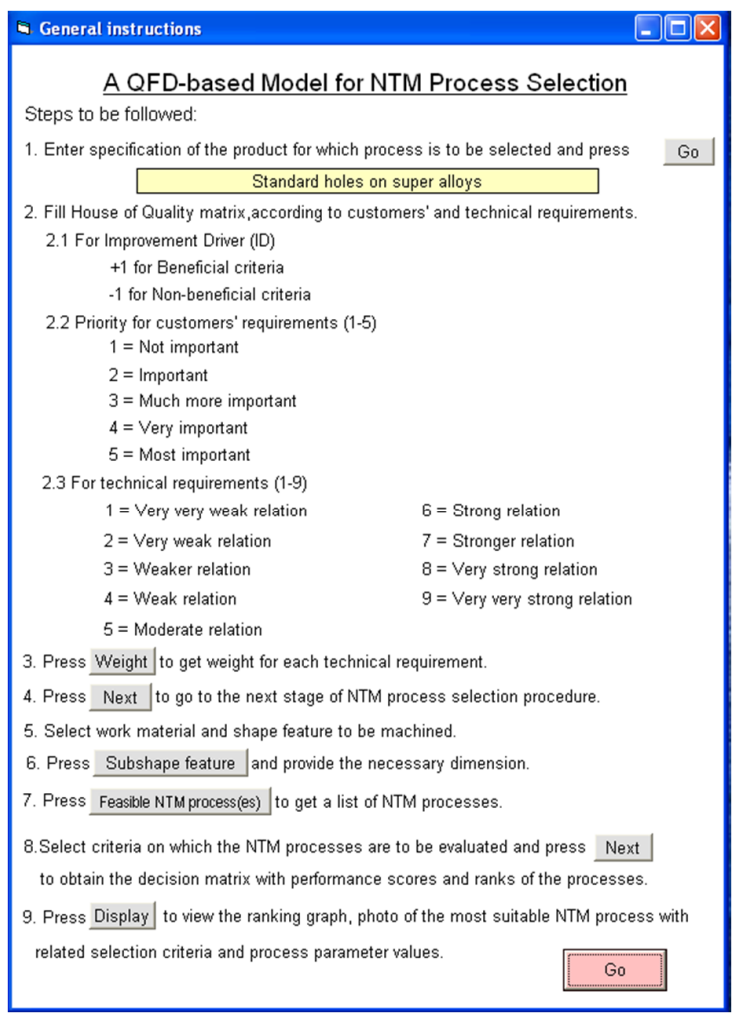

Fig. 1. Opening window of QFD-based NTM process selection model 


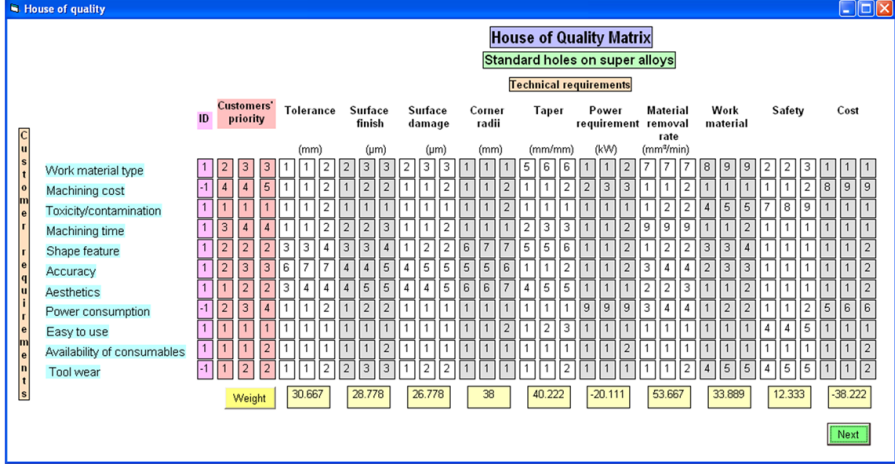

Fig. 2. Developed HOQ matrix for example 1

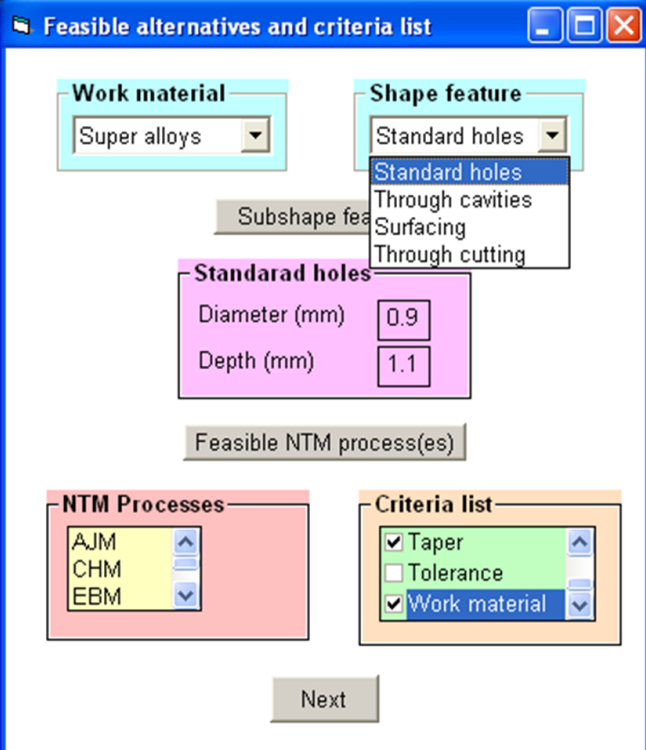

Fig. 3. Selection of work material and shape feature combination for example 1

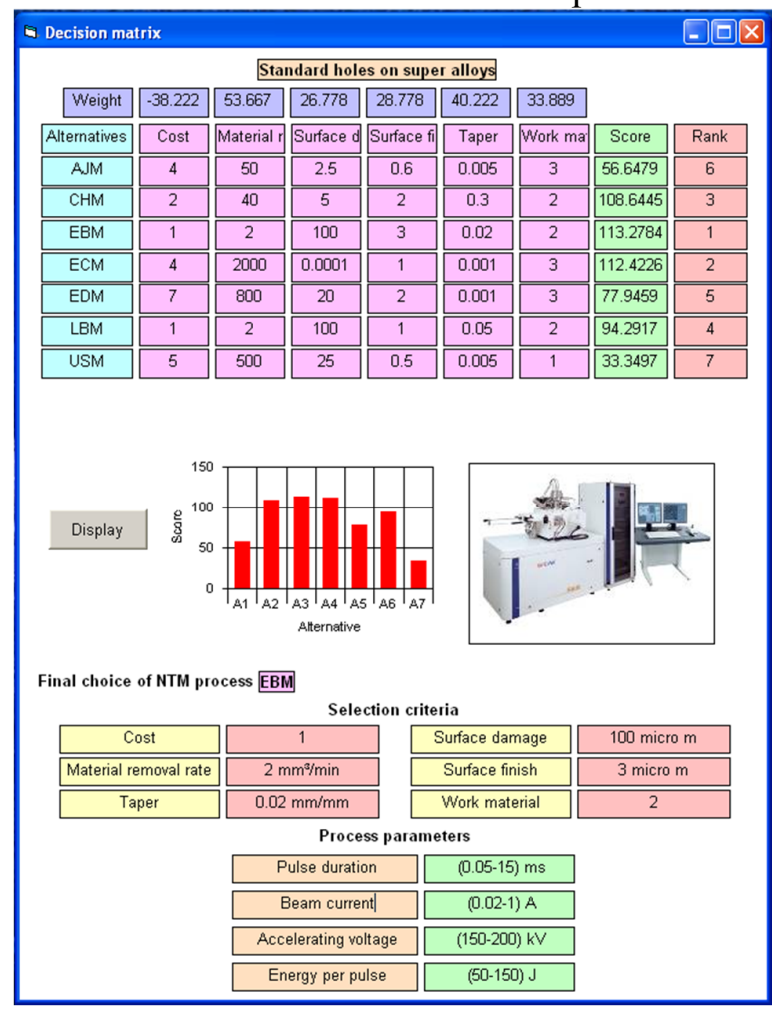

Fig. 4. Output for example 1

\subsection{Example 2: standard through cavities on ceramics}

Here, the process engineer wants to select the most suitable NTM process in order to generate standard through cavities (with $\mathrm{t} / \mathrm{w}<10$, where $\mathrm{t}=$ through cavity depth and $\mathrm{w}=$ through cavity width) on ceramic work materials. The corresponding HOQ matrix is exhibited in Fig. 5, from which the priority weights of all the technical requirements (process characteristics) of NTM processes are obtained. Negative priority weights for power requirement and cost criteria signify that amongst the ten process characteristics, these two are of non-beneficial type, always requiring lower values. In the 
next window, as shown in Fig. 6, the user needs to input the type of the work material (ceramics) and sub-shape feature (standard through cavity) combination. Now, the developed model automatically identifies AJM, CHM, EBM, LBM, USM and WJM as the feasible NTM processes for generating standard through cavities on ceramics.

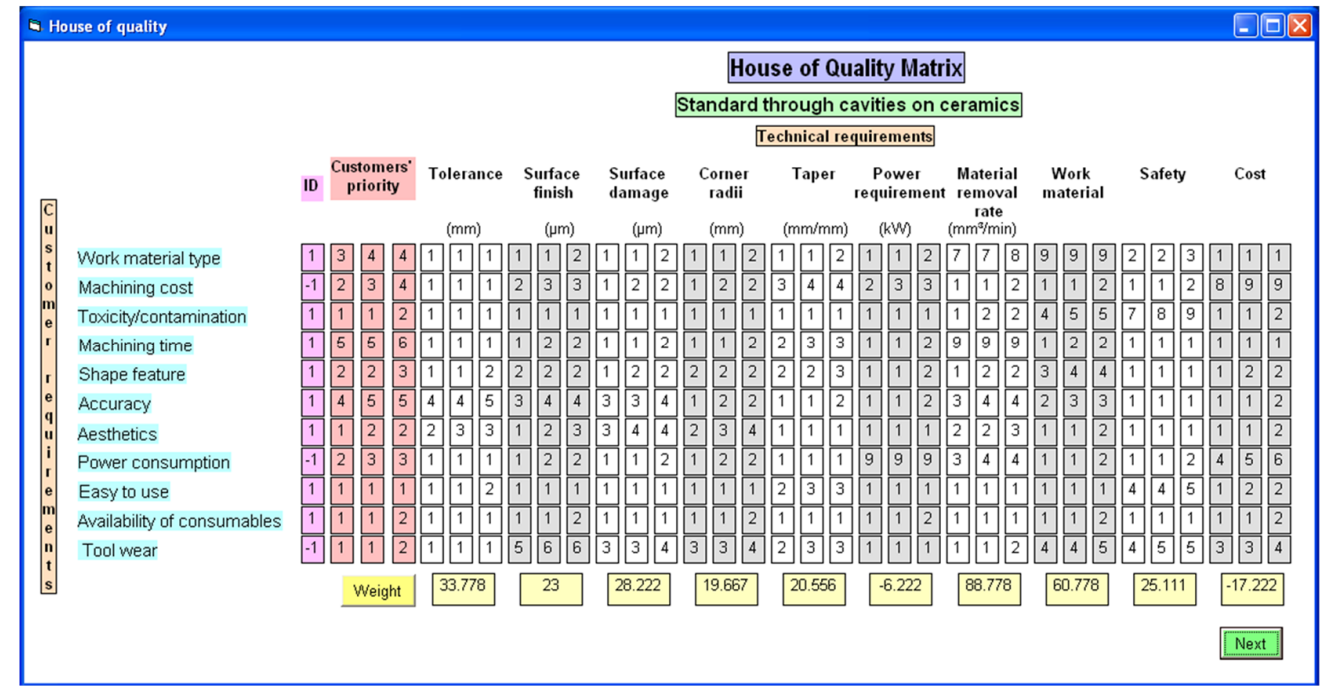

Fig. 5. Developed HOQ matrix for example 2
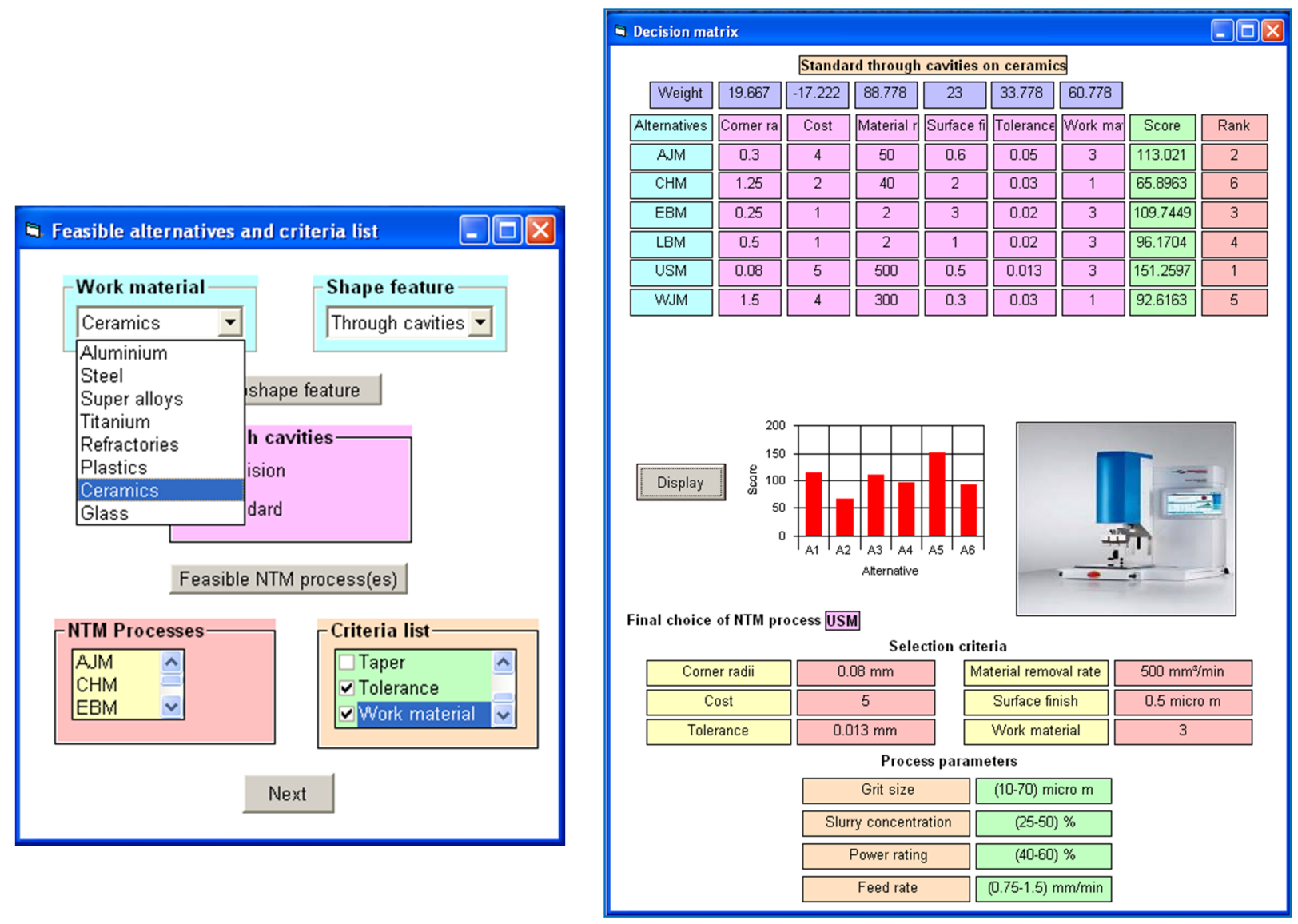

Fig. 6. Selection of work material and shape feature combination for example 2

Fig. 7. Output for example 2 
In Fig. 6, the user then selects corner radii, cost, tolerance, material removal rate, surface finish and work material as the final set of criteria based on which the most suitable NTM process would be identified from the set of six feasible processes. In Fig. 7, the final decision matrix for this NTM process selection problem is exhibited, as developed from the database of the model. It is shown that USM is the best NTM process, followed by AJM for the generation of standard through cavities on ceramics. Among the six feasible processes for the given application, CHM is the least preferred choice. For the same machining application, Karande and Chakraborty $\left(2012^{\mathrm{b}}\right)$ observed the ranking of the feasible NTM processes as USM-AJM-WJM-LBM-EBM-CHM while employing a reference point-based approach. On the other hand, this QFD-based model provides a rank ordering of the NTM processes as USM-AJM-EBM-LBM-WJM-CHM. It is interesting to note that in both the cases, the best and the worst choices of NTM process exactly match.

A photograph of an USM setup along with the values of its various process parameters as grit size $=$ $10-70 \mu \mathrm{m}$, slurry concentration $=25-50 \%$, power rating $=40-60 \%$ and feed rate $=0.75-1.5 \mathrm{~mm} / \mathrm{min}$ are also provided in Fig. 7. These are the tentative settings of the USM process parameters only to guide the process engineers. For attaining the desired machining performance, the identified USM process parameter settings need to be more preciously chosen. The list of the identified process parameters may also vary with the specifications and make of the USM setup.

\subsection{Example 3: deep through cutting on titanium}

In this example, deep through cutting operation on titanium material needs to be performed.

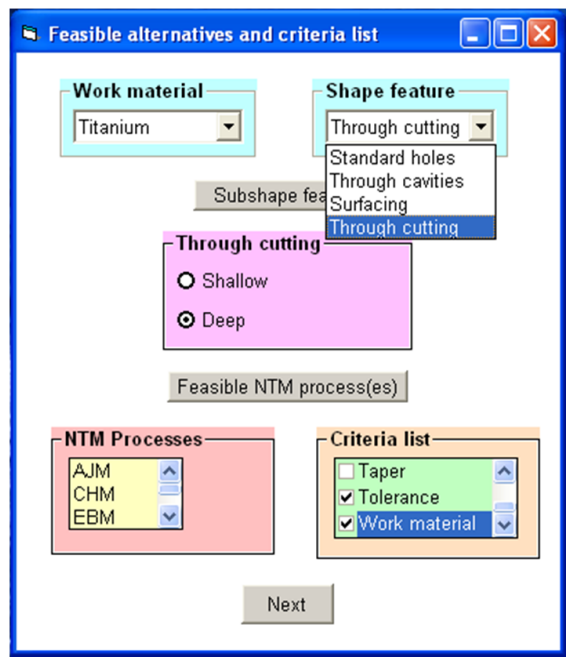

Fig. 8. Selection of material type and sub-shape feature for example 3

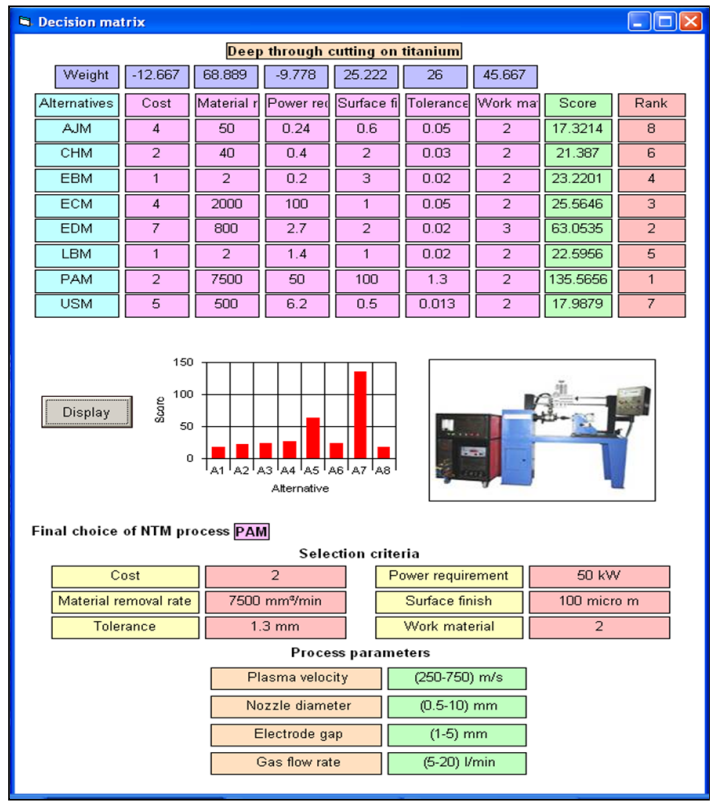

Fig. 9. Output for example 3

In Fig. 8, when the process engineer selects the material type as titanium, and shape and sub-shape feature combination as deep through cutting operation, the developed model automatically shortlists AJM, CHM, EBM, ECM, EDM, LBM, PAM and USM as the feasible NTM processes for the specified machining application. Then based on the capabilities of those NTM processes and end requirements of the final product, the desired process characteristics are chosen from the technical requirements list as cost, material removal rate, power requirement, surface finish, tolerance and work material which would ultimately drive towards the selection of the most appropriate NTM process. In Fig. 9, the corresponding decision matrix along with performance scores and ranks of the shortlisted NTM processes are automatically generated. In this case, cost and power requirement are the non- 
beneficial attributes having negative priority weights. It is observed that for performing deep through cutting operation on titanium, PAM is the most suitable NTM process, followed by EDM process. The capabilities of PAM process are also extracted as cost $=2$ (low), material removal rate $=7500$ $\mathrm{mm}^{3} / \mathrm{min}$, tolerance $=1.3 \mathrm{~mm}$, power requirement $=50 \mathrm{~kW}$, surface finish $=100 \mu \mathrm{m}$ and work material $=2$ (moderate). This output from the developed model would also guide the process engineers in selecting the related PAM process parameters as plasma velocity $=250-750 \mathrm{~m} / \mathrm{s}$, nozzle diameter $=0.5-10 \mathrm{~mm}$, electrode gap $=1-5 \mathrm{~mm}$ and gas flow rate $=5-20 \mathrm{l} / \mathrm{min}$, although fine tuning of those displayed process parameters is necessary to obtain the enhanced machining performance.

\subsection{Example 4: double contouring on duralumin}

Here, double contouring operation on duralumin (an aluminium alloy) needs to be performed using a suitable NTM process. Double contouring is a sub-feature of surfacing operation.
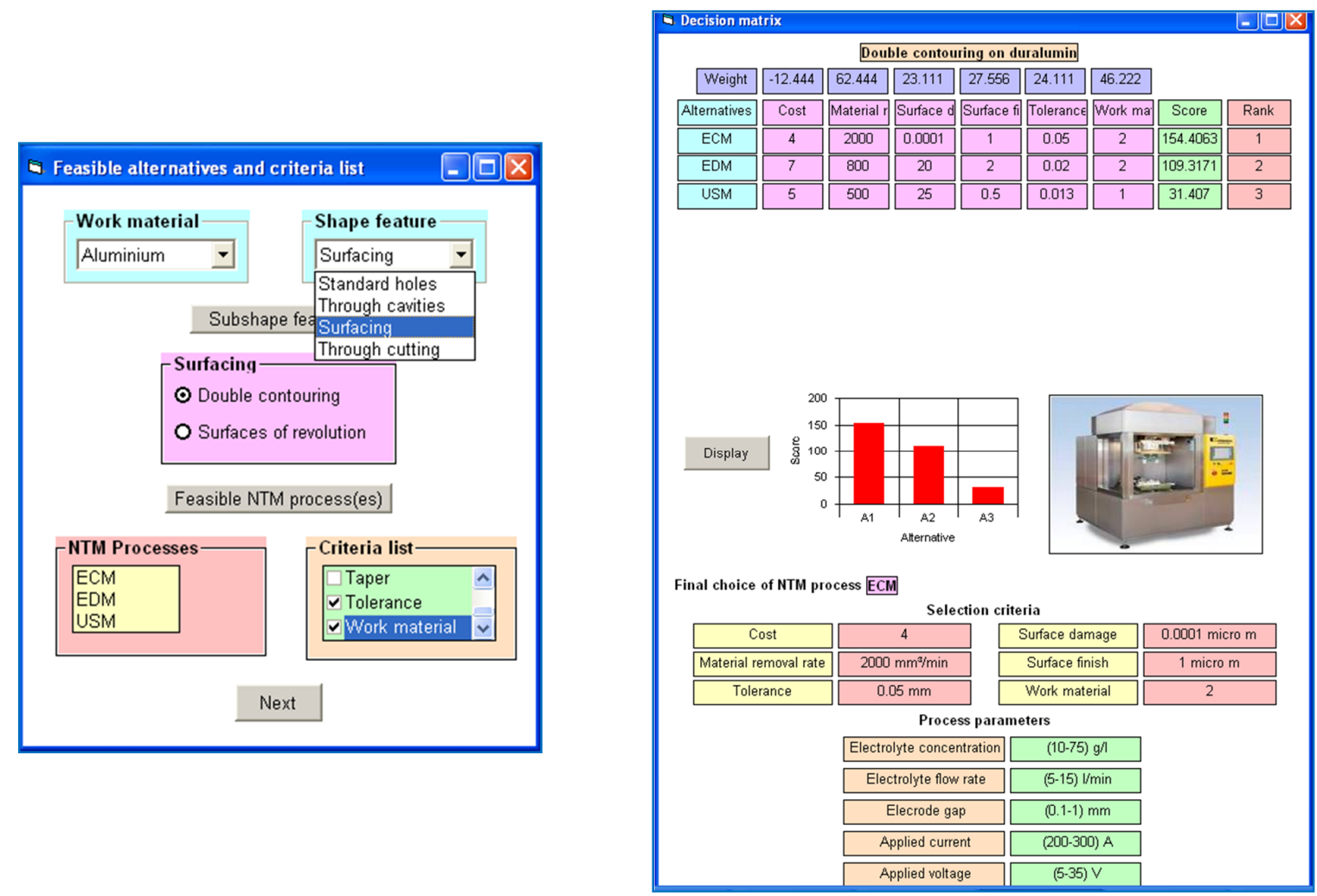

Fig. 10. Material type and sub-shape feature selection for example 4

Fig. 11. Output for example 4

In Fig. 10, after selecting the suitable work material and shape feature combination for the given machining application, when the user presses the 'Feasible NTM process(es)' functional key, ECM, EDM and USM get shortlisted as the feasible NTM processes being capable to perform the specified machining operation. Now the performances of these three NTM processes are evaluated based on cost, material removal rate, surface damage, surface finish, tolerance and work material criteria as set by the user in Fig. 10. Pressing of the 'Next' key helps the user to jump to the final NTM process selection window, as provided in Fig. 11. The priority weights of the identified criteria would automatically be supplied from the corresponding HOQ matrix. A negative priority weight for cost criterion identifies it as a non-beneficial attribute for the given problem. The original decision matrix, extracted from the database, is also shown in Fig. 11 along with the calculated performance scores and ranks of the three feasible NTM processes. It is observed that ECM is the best method, amongst the three NTM processes, for double contouring operation on duralumin alloy. The photograph of a 
typical ECM setup is also provided in Fig. 11. Now, the process engineer may select the ECM process along with its various machining parameters suggested as electrolyte concentration $=10-75$ $\mathrm{g} / \mathrm{l}$, electrolyte flow rate $=5-15 \mathrm{1} / \mathrm{min}$, inter-electrode gap $=0.1-1 \mathrm{~mm}$, applied current $=200-300 \mathrm{~A}$ and applied voltage $=5-35 \mathrm{~V}$. However, a fine tuning of all these ECM process parameters is finally required for achieving the desired machining performance.

\section{Conclusions}

In this paper, a decision-making model is developed while integrating quality function deployment for selecting the most suitable NTM process from a large number of available alternatives for generating a desired shape feature on a given work material. It also acts like an expert system to ease out and automate the NTM process selection procedure. It not only helps in selecting the best NTM process but also provides a comparative study among the alternative processes. Its main advantage is that it does not require, from the point of view of the process engineers, to have any in-depth technological knowledge regarding the applicability of various NTM processes. Moreover, it relieves the process engineers from committing errors in the decision-making procedure while considering the process and product characteristics related to the selection of the optimal NTM process. It can also be implemented in a group decision-making environment involving the opinions of three process engineers/decision makers. It can be made more dynamic and versatile by including the hybrid NTM processes, shape features and materials yet to come in near future.

\section{References}

Akao, Y. (1990). Quality Function Deployment, Cambridge. MA: Productivity Press.

Chakraborty, S., \& Dey, S. (2006). Design of an analytic-hierarchy-process-based expert system for non-traditional machining process selection. International Journal of Advanced Manufacturing Technology, 31(5-6), 490-500.

Chakraborty, S., \& Dey, S. (2007). QFD-based expert system for non-traditional machining processes selection. Expert Systems with Applications, 32(4), 1208-1217.

Chakraborty, S. (2011). Applications of the MOORA method for decision making in manufacturing environment. International Journal of Advanced Manufacturing Technology, 54(9-12), 1155-1166.

Chan, L-K., \& Wu, M-L. (2002). Quality function deployment: A literature review. European Journal of Operational Research, 143(3), 463-497.

Chan, L-K., \& Wu, M-L. (2005). A systematic approach to quality function deployment with a full illustrative example. Omega, 33(2), 119-139.

Chatterjee, P., \& Chakraborty, S. (2013). Nontraditional machining processes selection using evaluation of mixed data method. International Journal of Advanced Manufacturing Technology, 68(5-8), 1613-1626.

Coğun, C. (1993). Computer-aided system for selection of nontraditional machining operations. Computers in Industry, 22(2), 169-179.

Das, S., \& Chakraborty, S. (2011). Selection of non-traditional machining processes using analytic network process. Journal of Manufacturing Systems, 30(1), 41-53.

Das Chakladar, N., \& Chakraborty, S. (2008). A combined TOPSIS-AHP-method-based approach for non-traditional machining processes selection. Proceedings of the Institution of Mechanical Engineers, Part B, Journal of Engineering Manufacture, 222(12), 1613-1623.

Das Chakladar, N., Das, R., \& Chakraborty, S. (2009). A digraph-based expert system for nontraditional machining processes selection. International Journal of Advanced Manufacturing Technology, 43(3-4), pp. 226-237.

Edison Chandrasselan, R., Jehadeesan, R., \& Raajenthiren, M. (2008). Web-based knowledge base system for selection of non-traditional machining processes. Malaysian Journal of Computer Science, 21(1), 45-56.

Govers C.P.M. (1996). What and how about quality function deployment (QFD). International Journal of Production Economics, 46-47, 575-585. 
Hauser, J.R., \& Clausing, O. (1988). The house of quality. Harvard Business Review, May-June, 6373.

Jain, V.K. (2005). Advanced Machining Processes. New Delhi: Allied Publishers Pvt. Limited.

Karande, P., \& Chakraborty, S. (2012 $\left.{ }^{\mathrm{a}}\right)$. Application of PROMETHEE-GAIA method for nontraditional machining processes selection. Management Science Letters, 2(6), 2049-2060.

Karande, P., \& Chakraborty, S. $\left(2012^{\mathrm{b}}\right)$. A reference point-based approach for non-traditional machining process selection. Proceedings of the $4^{\text {th }}$ International and $25^{\text {th }}$ AIMTDR Conference, India, 1247-1252.

Pandey, P.C., \& Shan, H.S. (1981). Modern Machining Processes. New Delhi: Tata McGraw-Hill Publishing Com. Ltd.

Sadhu, A., \& Chakraborty, S. (2011). Non-traditional machining processes selection using data envelopment analysis (DEA). Expert Systems with Applications, 38(7), 8770-8781.

Temuçin, T., Tozan, H., Vayvay, Ö., Harničárová, M., \& Valíček, J. (2014). A fuzzy based decision model for nontraditional machining process selection. International Journal of Advanced Manufacturing Technology, 70(9-12), 2275-2282.

Yurdakul, M., \& Coğun, C. (2003). Development of a multi-attribute selection procedure for nontraditional machining processes. Proceedings of the Institution of Mechanical Engineers, Part B, Journal of Engineering Manufacture, 217(7), pp. 993-1009. 